\title{
Comments on Chavent et al.: Renovascular hypertension: results in adulthood of renal autotransplantation performed in children
}

\author{
Nellie Della Schiava ${ }^{1} \cdot$ Patrick Lermusiaux $^{1}$
}

Received: 7 June 2017 / Accepted: 12 June 2017 / Published online: 10 July 2017

(C) IPNA 2017

\section{Dear Editors,}

In their recently published article entitled "Renovascular hypertension: results in adulthood of renal autotransplantation performed in children", Chavent et al. present good long-term results for renal autotransplantation performed in children [1]. However, we would like to draw attention to the potential complications of this surgery that are not mentioned in this paper. The surgical technique is not described in the Methods, but in the Discussion, where the authors mention that they used arterial graft as a substitute. To our knowledge, it is the internal iliac artery which is the usual arterial graft for this type of surgery. Yet, as we showed in 2013 [2], the occlusion of the internal iliac artery can lead to such complications as buttock claudication. This complication may be disabling, especially in young patients, and surgical repair is very difficult or impossible. Moreover, case series have shown other complications, such as erectile dysfunction [3]. This complication is alarming for young male patients. We are very interested to know if the use of internal iliac artery in these young patients is a safe technique in the short and long term.

Compliance with ethical standards

Conflicts of interest The authors have no conflicts to declare.

\section{References}

1. Chavent B, Duprey A, Lavocat MP, Fichtner C, Beraud AM, Albertini JN, Favre JP, Maillard N, Barral X (2017) Renovascular hypertension: results in adulthood of renal autotransplantation performed in children. Pediatr Nephrol. doi:10.1007/s00467-017-3664-x

2. Millon A, Paquet Y, Ben Ahmed S, Pinel G, Rosset E, Lermusiaux P (2013) Midterm ouctomes of embolization of internal iliac artery aneurysms. Eur J Vasc Endovasc Surg 45:22-27

3. Rayt HS, Bown MJ, Lambert KV, Fishwick NG, McCarthy MJ, London NJ, Sayers RD (2008) Buttock claudication and erectile dysfunction after internal iliac artery embolization in patients prior to endovascular aortic aneurysm repair. Cardiovasc Intervent Radiol $31: 728-734$
Nellie Della Schiava

dellaschiava.nellie@neuf.fr

1 Departement of vascular and endovascular surgery, Hôpital Edouard Herriot, 5 Place d'Arsonval, Lyon Cedex 03, France 